\title{
Modelling and Simulation of Natural Fibre/Epoxy Composites - Prediction
} of Stress State and Deformations

Prabhakaran, R.T. Durai; Gupta, Mohit; Mahajan, Puneet; Ormondroyd, Graham A.

\section{International Journal of Materials Engineering Innovation}

DOI:

10.1504/IJMATEI.2019.10021337

Published: 01/01/2019

Peer reviewed version

Cyswllt i'r cyhoeddiad / Link to publication

Dyfyniad o'r fersiwn a gyhoeddwyd / Citation for published version (APA):

Prabhakaran, R. T. D., Gupta, M., Mahajan, P., \& Ormondroyd, G. A. (2019). Modelling and Simulation of Natural Fibre/Epoxy Composites - Prediction of Stress State and Deformations. International Journal of Materials Engineering Innovation, 10(2).

https://doi.org/10.1504//JMATEI.2019.10021337

\footnotetext{
Hawliau Cyffredinol / General rights

Copyright and moral rights for the publications made accessible in the public portal are retained by the authors and/or other copyright owners and it is a condition of accessing publications that users recognise and abide by the legal requirements associated with these rights. study or research

- Users may download and print one copy of any publication from the public portal for the purpose of private

- You may not further distribute the material or use it for any profit-making activity or commercial gain

- You may freely distribute the URL identifying the publication in the public portal ?
}

Take down policy

If you believe that this document breaches copyright please contact us providing details, and we will remove access to the work immediately and investigate your claim. 


\title{
Modelling and Simulation of Natural Fibre/Epoxy Composites - Prediction of Stress State and Deformations
}

\author{
R.T. Durai Prabhakaran* (1), Mohit Gupta ${ }^{(2)}$, Puneet Mahajan ${ }^{(2)}$, and Graham A Ormondroyd ${ }^{(1)}$ \\ (1) The BioComposites Centre, Bangor University, Bangor Gwynedd, North Wales, UK \\ (2) Department of Applied Mechanics, Indian Institute of Technology, New Delhi, India \\ *Corresponding Author Email: duraiprabhakaran@gmail.com
}

\begin{abstract}
Natural fibres usually include hemp, jute, and flax fibres are gaining importance in composites with an increasing potential to replace synthetic fibres in advanced composites. Current glass and carbon fibre systems require large amount of energy in production, which has led to an upsurge in interest in the reinforcement potential of natural fibres. To improve composite performance, designers try different possibilities i.e. vary material thickness (lamina), fibre volume fraction, fibre weight ratio, fibre orientation, and fibre layups. Especially with natural fibres, higher variability of mechanical properties is a major challenge due to fibre parameters such as lignin content, pectin content and degree of polymerisation. Therefore, prediction of laminate performance at early stages of design requires computation.

The present work is intended to understand how the flax fibre layups and orientation affect the mechanical behaviour of layered laminated composites. Unidirectional $[0]_{4 S}$, crossply $[0 / 90]_{2 s}$, angle-ply [+45/-45] $]_{2 \mathrm{~S}}$, and quasi-isotropic [0/90/45/-45]s laminates made up of flax fibre reinforced epoxy composites are considered to study tensile, flexural behaviour, and stress distribution in the individual laminae. A classical laminate plate theory (CLPT), which considers the elastic behaviour of the laminae, and a numerical simulation method based on finite element modelling (FEM) are used to predict the stress-strain response of a layered composite. Further, the analytical results and the numerical predictions show that the quasiisotropic flax/epoxy laminate perform better than angle-ply and cross ply laminates.
\end{abstract}

\section{Keywords}

Natural fibre, Epoxy, Flexural Loads, Cross/Angle-ply, Plate Theory, FE analysis 


\section{INTRODUCTION}

Bio-based composites are the future materials for lightweight industrial structures, having greater capability to replace current conventional composite materials (bio-derived resin in place of synthetic resins, similarly replacing glass or carbon fibres with natural fibrous materials) [1-3]. Naturally available fibrous materials are derived either from agricultural waste and or from forestry [4]. These fibres are being utilized it in the structural composites due to their eco-friendly nature and sustainability [5]. Energy and carbon credits from end of life incineration of natural fibres favours their usage in the automotive sector, construction industry, electronic casings, and in furniture industry [6-8].

A few articles have demonstrated the benefits and performance of natural fibres for composite applications [9-15]. It has been noted that some issue that natural fibres face include accentuated sensitivity to water and moisture resulting in composite durability problems, and incompatibility with hydrophobic polymers leading to poor fibre/matrix interface [16-17]. Flax fibres have higher strength and stiffness compared to other natural fibres such as hemp, sisal, jute, and coir fibres. Scientists have focused their attention on further improving flax fibre properties either by modifying fibre surface morphology and or by designing optimum fibre surface coatings [18-19]. The parameters of flax pre-forms such as lignin content, pectin content and degree of polymerisation show higher variability and severely degrade mechanical properties of flax/epoxy composites. Especially for layered composites, fibre waviness, fibre tows alignment, weft yarns used in flax fabrics influence the stress state in a laminate. To understand deformation and stress fields generated during mechanical loading of layered composite, mathematical and simulation models derived from continuum mechanics are used.

From the literature review [20-23], it is clear that some experimental investigations have been conducted to understand stresses in a layered flax/epoxy composite. George et al. [15-17] studied the influence of processing and chemical treatment of flax fibres and composites. The work extended to evaluate the alkaline fibre treatment and its effect on longitudinal and transverse properties of unidirectional composites. Cerbu [10] studied mechanical behaviour of flax/epoxy and flax/glass/epoxy composites, where bidirectional flax woven fabrics are considered. Performance of bidirectional eight layered flax/epoxy composites showed higher mechanical properties in weft direction when compared to warp direction. Young's modulus in tensile $(33.84 \%)$ /bending $(13.44 \%)$ and normal tensile stress $(40.63 \%) /$ bending stress $(12.69 \%)$ is greater for weft direction compared to warp direction of 
the specimen. Similarly, Durai Prabhakaran et. al. [11-12] studied flexural performance of biaxial $\left( \pm 45^{0}\right)$ non-crimp glass and flax fabrics (refer Figure 1a) with super-sap epoxy resin. Symmetrical laminates with layered configuration were produced to demonstrate the effect of hybridization of flax/glass layups on bending properties. To determine strength of composite, experiments are generally conducted on specimens subjected to loads that can produce simple stress fields and determining the load at which composite specimen fails. With these experimental approach, yield strength and ultimate strength can be obtained under uniaxial tensile and compression loading conditions. Determining stress/strain fields in individual laminae and their failure is difficult through experimental approach. Therefore, analytical and numerical models help to predict stress-strain fields in each laminae of layered composites.

Several articles described theoretical development of higher-order three dimensional elasticity theories for layered composite laminate to account displacements, stress fields, and shear deformation. Reissner and Stavsky [24] proposed the first order lamination plate theory. Later the models are extended from thin/thick plates to laminated anisotropic plates. Whitney and Pagano [25], and J.N. Reddy et. al. [26-28] derived 3-D elasticity solution for a bidirectional composite plate, which reveals the nonlinearity of in plane displacements in any layer with respect to thickness of the plate. Sarvestani et al. [29] formulated theoretical model combining first-order shear deformation theory and layerwise theory for bending analysis of cross-ply laminate. Results obtained from the model are compared with three dimensional elasticity solution, the close agreement of result verifies the accuracy of the layerwise theory developed by the authors [29].

From the literature survey [27-29], it appears that laminate failure in bending is much more often than the in-plane loads [30]. Limited research carried out to understand natural fibre reinforced composites by theoretical and numerical models. The present study is motivated by the lack of three-dimensional elasticity and finite-element solution for flax fibre/epoxy composites with symmetric layups subjected to tensile and bending loads, as shown in Figure 1c. Theoretical and numerical analysis has been undertaken to determine stresses and mid-span deflections in a layered composites i.e. unidirectional [0] $]_{4 \mathrm{~S}}$, cross-ply [0/90] 2 , angle-ply [+45/$45]_{2 \mathrm{~S}}$, and quasi-isotropic [0/90/45/-45]S laminates made up of flax fibre reinforced epoxy composites. Classical laminate plate theory (CLPT) and finite element (FE) simulation have been used to examine the stress distribution in the symmetric laminates of flax/epoxy composites under tensile and flexural loading conditions. For the simulation of stresses, Solidworks® version 2018 software (Dassault Systems, UK) was used. 


\section{ANALYTICAL MODELS}

Theoretical model defined in this section is a most commonly used analytical model based on micromechanics of materials. Several micromechanical models exists in literature to evaluate the mechanical behaviour of layered composite beams. In the present study, classical laminate plate theory (CLPT) was considered to predict stresses and strains in individual laminae owing to external loads on the laminate [27-28].

\section{Classical Laminate Plate Theory (CLPT)}

Consider a laminated plate with $\mathrm{N}$ layers of orthotropic laminae, each being oriented arbitrarily with respect to the laminate $(\mathrm{x}, \mathrm{y})$ co-ordinates, which are taken to be in the midplane of the laminate. The displacements $\left(\mathrm{u}_{1}, \mathrm{u}_{2}, \mathrm{u}_{3}\right)$ at a point $(\mathrm{x}, \mathrm{y}, \mathrm{z})$ in the laminate are calculated with the following expression [28]:

$$
\begin{gathered}
u_{1}(x, y, z)=u(x, y)+U(x, y, z) \\
u_{2}(x, y, z)=v(x, y)+V(x, y, z) \\
u_{3}(x, y, z)=w(x, y)
\end{gathered}
$$

where $(\mathrm{u}, \mathrm{v}, \mathrm{w})$ are the displacements of $\operatorname{apoint}(\mathrm{x}, \mathrm{y}, 0)$ on the reference plane of the laminate.

According to the classical laminate plate theory (CLPT), the laminate plate made of several layers of either same or different materials are placed either symmetrically or nonsymmetrically to the median surface. In the current study symmetric layers with the same thickness and same material are considered to define a composite laminate (Figure 1). Laminates $\left[0^{0}\right]_{4 \mathrm{~S}},[0 / 90]_{2 \mathrm{~S}},[+45 /-45]_{2 \mathrm{~S}}$, and quasi-isotropic $[0 / 90 / 45 /-45]_{\mathrm{S}}$ are defined as symmetric transversely orthotropic laminated conditions. The stresses in a laminate vary from layer to layer, as well strains vary linearly across the beam thickness in spite of having laminae with different directional properties [20].

\section{TABLE 1}

Rule of mixtures did not account fibre kinking or surface treatment for flax fibres (refer Figure 1b). Therefore, experimentally measured properties or properties which take kinking into account are presented in Table 1. From Table 1, using the constituent properties of fibre and matrix, stiffness matrix for a laminae can be defined as:

Stiffness Matrix $[\mathrm{S}]=\left[\begin{array}{ccc}Q_{11} & Q_{12} & 0 \\ Q_{21} & Q_{22} & 0 \\ 0 & 0 & Q_{66}\end{array}\right]$ 
where $Q_{11}=\frac{E_{L}}{1-\vartheta_{L T} \vartheta_{T L}} ; \quad Q_{22}=\frac{E_{T}}{1-\vartheta_{L T} \vartheta_{T L}} ; \quad Q_{12}=\frac{\vartheta_{T L} E_{L}}{1-\vartheta_{L T} \vartheta_{T L}} ; Q_{66}=G_{L T} ;$

$\vartheta_{L T} E_{T}=\vartheta_{T L} E_{L}$

According to CLPT theory [20], total plate constitutive equation of a multi-layered laminate is used to calculate force and moment resultants

$\left[\begin{array}{l}N \\ M\end{array}\right]=\left[\begin{array}{ll}A & B \\ B & D\end{array}\right]\left[\begin{array}{c}\varepsilon_{0} \\ k\end{array}\right]$

where strains and plate curvatures are estimated by using

$\varepsilon_{0}=\frac{\partial u_{0}}{\partial x} \quad k=-\frac{\partial^{2} w}{\partial x^{2}}$

The elements of matrix [A], [B], and [D] are defined by equation (7), as shown below:

$A_{i j}=\sum_{k=1}^{n}\left(\bar{Q}_{i j}\right)_{k}\left(h_{k}-h_{k-1}\right) \quad B_{i j}=\frac{1}{2} \sum_{k=1}^{n}\left(\bar{Q}_{i j}\right)_{k}\left(h_{k}^{2}-h_{k-1}^{2}\right)$

$D_{i j}=\frac{1}{3} \sum_{k=1}^{n}\left(\bar{Q}_{i j}\right)_{k}\left(h_{k}^{3}-h_{k-1}^{3}\right)$

[A], $[\mathrm{B}],[\mathrm{D}]$ matrices for the eight layered symmetric flax/epoxy laminates $\left[0^{0}\right]_{4 \mathrm{~S}},[0 / 90]_{2 \mathrm{~S}}$, $[+45 /-45]_{2 S}$, and quasi-isotropic [0/90/45/-45] san be estimated from the lamina (or each ply) transformed stiffness matrix elements. Stresses in each lamina and the mid-span deflections of the composite beam are estimated for symmetric laminates.

\section{In Plane Tensile Loading}

Considering the layered composite beam section as shown in Fig 2 subjected to in-plane tensile loading are analysed to compute stresses and strains. Using CLPT, stresses and strains in the individual laminae can be estimated using

$$
\begin{aligned}
& \left\{\begin{array}{c}
\sigma_{x} \\
\sigma_{y} \\
\tau_{x y}
\end{array}\right\}_{k}=[\bar{Q}]_{k}\left\{\left\{\begin{array}{c}
\varepsilon_{x}^{0} \\
\varepsilon_{y}^{0} \\
\gamma_{x y}^{0}
\end{array}\right\}+z\left\{\begin{array}{c}
k_{x} \\
k_{y} \\
k_{x y}
\end{array}\right\}\right\} \\
& \left\{\begin{array}{c}
\varepsilon_{x} \\
\varepsilon_{y} \\
\gamma_{x y}
\end{array}\right\}_{k}=\left\{\begin{array}{c}
\varepsilon_{x}^{0} \\
\varepsilon_{y}^{0} \\
\gamma_{x y}^{0}
\end{array}\right\}+z_{k}\left\{\begin{array}{c}
k_{x} \\
k_{y} \\
k_{x y}
\end{array}\right\} \\
& {\left[\begin{array}{c}
N_{x} \\
N_{y} \\
N_{x y}
\end{array}\right]=\left[\begin{array}{lll}
A_{11} & A_{12} & A_{16} \\
A_{12} & A_{22} & A_{26} \\
A_{16} & A_{26} & A_{66}
\end{array}\right]\left\{\begin{array}{c}
\varepsilon_{x}^{0} \\
\varepsilon_{y}^{0} \\
\gamma_{x y}^{0}
\end{array}\right\}}
\end{aligned}
$$


For the in-plane tensile loads: the elements in the matrix equation (10) are defined as $\mathrm{N}_{\mathrm{x}}$ is $200 \mathrm{~N}, \mathrm{~N}_{\mathrm{y}}$ is zero, and $\mathrm{N}_{\mathrm{xy}}$ is zero. Laminae strains can be estimated using equation (9) and (10). The stress values can be determined using equation (8).

\section{Three Point Bending}

Considering the laminate section as shown in Fig 3b assuming beam subjected to 3-point bending as defined in Figure 3a. The differential equation of deformed section of layered composite is derived from plate theory (CLPT) as

$$
\frac{d^{2} w_{0}}{d x^{2}}=-\frac{M}{E_{x} I}
$$

When loading is prescribed on a layered composite, the deformation results in terms of midplane strains and plate curvatures of the midplane can be calculated. The deformation can be estimated using equation (1) and visualized as shown in Figure 4 for a symmetric plate subjected to pure bending. Using equation (5) and equation (7), plate curvatures for an orthotropic laminae referred to arbitrary axes can be determined by using equation (9)

$$
\left\{\begin{array}{l}
M_{x} \\
M_{y} \\
M_{x y}
\end{array}\right\}=\left[\begin{array}{lll}
D_{11} & D_{12} & D_{16} \\
D_{21} & D_{22} & D_{26} \\
D_{61} & D_{62} & D_{66}
\end{array}\right]\left\{\begin{array}{c}
k_{x} \\
k_{y} \\
k_{x y}
\end{array}\right\}
$$

Applying simply supported beam boundary conditions and solving the above equation leads to the following flexural properties (modulus, mid-span deflection, and bending stress) [20]:

$$
\begin{gathered}
E_{x}=\frac{12}{h^{3} D^{-1} 11} \\
w_{0}=-\frac{F l^{2}}{48 E_{x} I} x\left[3-\left(\frac{2 x}{l}\right)^{2}\right] \quad w_{0_{\max }}=\frac{F l^{3}}{48 E_{x} I} \\
\left(\sigma_{\max }^{f}\right)=\frac{3 F_{\max } l}{2 b h^{2}}\left(1+6\left(\frac{w_{\max }}{l}\right)^{2}-3\left(\frac{w_{\max } h}{l^{2}}\right)\right)
\end{gathered}
$$




\section{NUMERICAL FE MODELLING}

Finite element models were developed using SOLIDWORKS® version 2018 (Dassault Systems, UK) to help understand tensile and flexural behaviour (analysis of stresses, strains and displacements) of a symmetric laminate. To simulate the real material behaviour, it was necessary to define density and mechanical properties of the material in Solidworks as given in Table 1. For any simulation, geometry, material, and boundary conditions are defined. The flax/epoxy specimens considered in the study have symmetry and therefore, unidirectional and cross-ply will have symmetry in the ply sequence, material, and geometrical symmetry, whereas the angle-ply has no through thickness plane of symmetry for material orientation. FEM will give results very slightly better than CLT (nearly matches but not perfect solution), as no defects are taken and everything is assumed perfectly bonded. Density normally does not play any role unless body force are taken into consideration by specifying acceleration due to gravity as the input file. Even then gravity or body force is very low as compared to other forces and does not contribute much. Therefore, the current study compares CLT and FEM results for flax/epoxy layered composites.

To simulate tensile loading for a composite beam, specimen dimensions are chosen as per ISO standards 527-2:1996. Specimen geometry is $250 \times 25 \times 4 \mathrm{~mm}^{3}$, where tabs are considered at the specimen gripping area. The tab material dimensions are considered as Aluminium alloy 1060 plates with a dimension $50 \times 25 \times 2 \mathrm{~mm}^{3}$. A tensile load of $200 \mathrm{~N}$ is applied in axial $\mathrm{X}$-direction as shown in Figure 2. SolidWorks used the directions $\mathrm{X}, \mathrm{Y}$, and Z of the global Cartesian system of coordinates having mixed mesh with curvature-based mesh having four Jacobian points having total nodes 63107, and elements 37256 (refer Figure 9a).

\section{-FIGURE 6}

\section{-FIGURE 7}

Similarly, to simulate 3-point bending with the "simply supported" assumption, the load and deflection follows linear relationship. In the current study, comparison of four symmetric laminates are analysed for bending, assuming load applied at centre of beam as $200 \mathrm{~N}$. The sum of reaction forces acting at supports are equal to $200 \mathrm{~N}$ in reverse direction to load applied. Specimen geometry is $80 \times 15 \times 4 \mathrm{~mm}^{3}$, where span (L) were set as $64 \mathrm{~mm}$ as shown in Figure 3. SolidWorks used the directions $\mathrm{X}, \mathrm{Y}$, and Z of the global Cartesian system of coordinates 
having mixed standard mesh with high quality having total nodes 3801, and elements 2182 (refer Figure 9b).

FIGURE 8

FIGURE 9

\section{RESULTS AND DISCUSSIONS}

Analytical models and finite element modelling (FEM) as a numerical method offers the possibility to quickly examine and evaluate laminate design at early stages of design long before a prototype is developed. The choice of natural fibres i.e. flax and hemp fibres rather than conventional fibres i.e. glass and carbon as fibre reinforcement yields a change of the final properties of the composite. One of the most relevant differences between the two kinds of fibres is their response to humidity. Unlike conventional fibres, cell-wall structure of plant fibres consists of chemical composition having polymers (cellulose and hemicellulose) combined with additional constituent's lignin, pectin, wax or oil and structural water demonstrates water sorption isotherms [31]. Bergès et. al. [32] investigated the effect of moisture uptake on monotonic tensile properties of flax/epoxy composites and induces an increase in the fatigue strength for a high number of cycles.

Twisting of fibres in flax yarns is a common problem refer figure $1 \mathrm{~b}$, which can influence on the stiffness of natural fibre composites. When the degree of twisting is increased, the fibres become more tightly configured within the yarns [33]. Resin penetration into highly twisted fibre yarns will get difficult and hence result in to poor impregnation characteristics, which can lead to porosity in the composites. To account "fibre yarn twisting" into micromechanical model, experiments are conducted to predict elastic constants using single layer composite. This considers the fibre yarn twisting while predicting stiffness in longitudinal and transverse directions, shear modulus, and Poisson's ratio. Another approach is to estimate the twisting angle using the sinus curve approach, which allows calculation of the (local) fibre orientation angle $\theta$ relative to the length direction (x-axis). The angle $\theta$ varies between zero and a maximum value, which is determined by the amplitude A relative to the sinus curve wave length $\lambda$, and thus by the fibre waviness [34]. In the present article, experimental approach is considered where single lamina properties are determined to account fibre yarn twisting. 
To predict natural fibre performance, very limited articles exists in literature to model the mechanical behaviour of a symmetric composites reinforced with flax fabrics. Analytical and numerical simulations for determining displacements and stress-strain fields of flax/epoxy composite subjected to tensile and bending loads are studied in this section.

FIGURE 10

\section{Effect of fibre orientation on lamina stress/strain}

Laminae material axes $(\mathrm{L}, \mathrm{T})$ oriented at an angle $\theta$ to the reference axes $(\mathrm{x}, \mathrm{y})$ will influence stresses and strains. From the CLPT, normal stresses $\left(\sigma_{x}\right.$ and $\left.\sigma_{y}\right)$ and normal strains $\left(\varepsilon_{x}\right.$ and $\left.\varepsilon_{y}\right)$ are coupled with shear strain $\left(\gamma_{x y}\right)$ and shear stresses $\left(\tau_{x y}\right)$. Similarly, when the normal stress $\sigma_{x}$ is applied other than fibre oriented longitudinal or transverse direction will result in produce of shear strains $\gamma_{x y}$. To define relationship between shear strain and normal stress, crosscoefficient $m_{x}$ and $m_{y}$ are defined [20]. Variation of the elastic constants as a function of fibre orientation $\theta$ for the flax/epoxy laminate are shown in Figure 11. Modulus $E_{x}$ decreases from $E_{L}$ at $\theta=0^{0}$ to $E_{T}$ at $\theta=90^{\circ}$, where the variation of modulus $E_{x}$ dependent on the shear modulus $G_{L T}$. From Figure 11, for flax/epoxy laminae the value of $E_{x}$ is less than modulus in longitudinal and transverse direction for values of $\theta$ between $45^{\circ}$ and $90^{\circ}$, similarly value of $G_{x y}$ is largest at $\theta=45^{\circ}$, and its variation is symmetric about this orientation. The cross-coefficients $m_{x}$ and $m_{y}$ are zero at $\theta=0^{0}$ and $\theta=90^{\circ}$, but for intermediate values of $\theta$, they recorded higher values.

\section{FIGURE 11}

\section{Effect of symmetry on stiffness elements}

The symmetry or asymmetry of a laminate based on angle, material, and thickness of plies, may cancel out some elements of the extensional stiffness [A], coupling stiffness [B], and bending stiffness $[D]$ matrices (refer equation 5). In the current work, laminates $\left[0^{0}\right]_{4 \mathrm{~S}},[0 / 90]_{2 \mathrm{~S}}$, $[+45 /-45]_{2 S}$, $[0 / 90 /+45 /-45]_{S}$ are considered as symmetry therefore elements of $[B]$ matrix is zero and elements of $\mathrm{Q}$ matrix for unidirectional and cross-ply i.e. $\left[\mathrm{Q}_{16}\right]$ and $\left[\mathrm{Q}_{26}\right]$ are zero. According to CLPT, symmetric laminates subjected to forces only have zero midplane curvatures reducing or zeroing out the coupling of forces and bending moments, normal and shear forces, or bending and twisting moments. For in-plane loads on symmetric laminates, 
bending-stretching coupling can be eliminated whereas for non-symmetric laminates undesirable warping owing to loads applied are observed. Laminates having angle/symmetry, and number of plies the same but change the stacking sequence influences the stress-strain fields.

TABLE 2

\section{In-Plane Loading for Stress-Strain Analysis}

For the current study, tensile and three-point bending configuration has been adopted to study flax/epoxy laminates. For tensile loading, axial force in the direction of fibre orientation F (200 $N$ ) is applied as shown in Figure 2. Therefore, the resultant force is defined as $N_{x}(200 N)$, and $\mathrm{N}_{\mathrm{y}}, \mathrm{N}_{\mathrm{xy}}$ are defined as zero, whereas the fibre direction coincides with the global axis for unidirectional laminates. As no other moments acting on composite, the resultant moments $\mathrm{M}_{\mathrm{x}}$, $\mathrm{M}_{\mathrm{y}}, \mathrm{M}_{\mathrm{xy}}$ are defined as zero. Similarly, to compare the laminate performance under bending, load $\mathrm{F}(200 \mathrm{~N})$ is applied at centre of beam, which is subjected to resultant moment $\mathrm{M}_{\mathrm{x}}(213.3$ N.m/m), $M_{y}, M_{x y}$ equal to zero. As no other forces acting on composite, resultant forces $N_{x}$, $\mathrm{N}_{\mathrm{y}}, \mathrm{N}_{\mathrm{xy}}$ are defined as zero, where the fibre direction coincides with the global axis for unidirectional and cross-ply laminates. Figure 5 demonstrates the variation of mid-span deflection for a symmetric laminate subjected to bending load. With equation 5, mid-plane strains and plate curvatures are estimated using stiffness and compliance matrices (refer Table 2). The stresses in a laminate vary from layer to layer, whereas strains vary linearly across the thickness even though the laminate is composed of laminae with varying directional properties [35 - 37]. Stresses and strains are calculated in each laminae both in global (x and y) and local material (1 and 2) directions. The distribution of a normal stresses $\left(\sigma_{x}, \sigma_{y}, \sigma_{1}\right.$, and $\left.\sigma_{2}\right)$, normal strains $\left(\varepsilon_{x}, \varepsilon_{y}, \varepsilon_{1}\right.$ and $\left.\varepsilon_{2}\right)$, shear strain $\left(\gamma_{x y}\right.$ and $\left.\gamma_{12}\right)$ and shear stress $\left(\tau_{x y}\right.$ and $\left.\tau_{12}\right)$ are plotted through the thickness of an eight-layered symmetric layups of unidirectional, cross-ply, angle-ply, and quasi-isotropic laminates subjected to in-plane tensile and bending loads as shown in Figure 6, 7 , and 8 . The basic difference between in-plane loading and flexural loading is that the strains are not the same in all layers of the laminate that has flexural loading.

\section{Unidirectional, Cross-Ply, and Angle-Ply Laminates}

Following principles of plate theory, stress-strain fields for each laminae can be defined using stiffness elements i.e. [A], [B], [D] matrices. Under in-plane loads with no bending loads, the 
symmetric laminate have the curvatures are defined as zero, therefore the strains are constant through the thickness. Figure 6 represents the individual laminae stress-strain fields that are estimated from the stiffness matrices, where the in-plane axial force applied to the eight-layered composite specimen in the longitudinal direction. Normal stress $\left(\sigma_{y}\right)$ is estimated as zero for unidirectional and angle-ply laminates, whereas for cross-ply has small stress field varying between the laminae. Similarly, shear stress $\left(\tau_{x y}\right)$ are defined as zero for unidirectional and cross-ply laminates, whereas for angle-ply laminate has shear stress acting across the thickness of the laminate. A 3D model has been established for simulation of the tensile test composite specimen, which enables to understand the tensile strength and individual ply stress fields. Eight ply flax/epoxy specimens with various stacking sequences were analysed for the stress and displacement predictions. The displacement at the free end of the specimen was found to maximum and zero at the clamped end whereas the significant reaction force was noticed at the clamped end during simulation. A good comparison was obtained between the CLPT results with the finite element model simulation data.

Figure 7 and 8 shows the individual ply stresses when a load $200 \mathrm{~N}$ is acting at centre of beam. For unidirectional and cross-ply, shear stress and midplane strains are zero because there are no in-plane forces acting and the laminate is symmetric. The state of stress through the thickness of the laminate (due to bending) results into laminate stiffness (estimated using equation (8) and (9). Figure 7 demonstrates the normal stress and shear stress variations across the thickness of laminates. Similarly, strain distribution through thickness of laminate is linear and plies used as outer contribute more to stiffness than inner layers of the laminate. Therefore bending stiffness for unidirectional is higher than cross-ply and angle-ply. From the analytical results, it has been shown that shear stress $\left(\tau_{\mathrm{xy}}\right)$ in angle-ply is higher than the normal stress $\left(\sigma_{\mathrm{y}}\right)$, and this leads to laminate twisting under bending loads. Shear stress for the unidirectional and cross-ply laminate are computed as zero, resulting no twisting.

Using SolidWorks, the distribution of the normal stress $\left(\sigma_{x}=S_{11}\right)$ across the thickness of the unidirectional laminate (ply 2) is shown in Figure 12. The stress values shown in the plots are in the second ply as $41.7 \mathrm{MPa}$, nearly matches with the analytical (CLPT) solution computed for each lamina, refer Figures 7. Similarly, the distribution of vertical displacement (mid-span deflection) of the laminate $W_{0 \max }$ in the direction of the $\mathrm{Z}$-axis are plotted in all four cases of laminate, as shown in Figure 10 and Table 3. The deflection obtained for the load (200 N) 
applied at centre of beam demonstrates unidirectional and cross-ply have better performance compared to angle-ply (deflection higher than $[0]_{4 S}$ and $[0 / 90]_{2 S}$ ).

\section{Quasi-Isotropic Laminate}

Quasi-isotropic laminates are in general not symmetric but they can be designed symmetric by mirroring a number of laminae to the mid-plane. Advantage of symmetric quasi-isotropic laminate is the coupling matrix $[B]$ is defined as zero. Flax/epoxy laminate with quasi-isotropic layup have extensional stiffness matrix $[A]$ is defined as isotropic with elastic constants defined as independent of fibre orientation in the plane. The stiffness elements i.e. $\left[A_{11}\right]$ and $\left[A_{22}\right]$ is $32290,\left[A_{16}\right]$ and $\left[A_{26}\right]$ is zero, whereas $\left[A_{11}-A_{12}\right]$ is equal to two times $\left[A_{66}\right]$ i.e. 11352 . The values obtained by CLPT satisfies the quasi-isotropic construction of plies.

The stress-strain fields for quasi-isotropic flax/epoxy laminate is shown in Figure 6, 7, 8. As the layup consists of $0 / 90$ on the outer layers which exhibits zero shear stress $\left(\tau_{\mathrm{xy}}\right)$ whereas the middle layers with fibre orientation of $+45 /-45$ defines shear stress values for the in-plane tensile loading as shown in Figure 6. In case of pure bending, laminates have shear stress $\left(\tau_{\mathrm{xy}}\right)$ values across the thickness of the laminate similar to angle-ply laminates. The laminate bending moduli (flexural moduli) is estimated by using equation 13, the values obtained for quasiisotropic and cross-ply are nearly equal to due its specially orthotropic and symmetric layups. The mid-span deflection are estimated using equation 14 and also predicted using finite element model are listed in Table 3, where the deflection of quasi-isotropic is better than angle-ply, but higher than cross-ply and unidirectional laminates.

TABLE 3

\section{CONCLUSIONS}

The work reports results obtained in numerical modelling of tensile and flexural behaviour of flax/epoxy composites with symmetrical layups (unidirectional, cross-ply, angle-ply, and quasi-isotropic) and these results are validated analytically using the classical laminate plate theory (CLPT). The static response of laminated flax/epoxy rectangular plates i.e. mid-span deflection, axial displacements, stress-strain fields are computed and compared for various symmetric flax/epoxy laminates with CLPT and FE numerical models. Based on the work, some conclusions may be drawn as follows: 
- Stiffness for the unidirectional laminates is greater than cross-ply, angle-ply, and quasiisotropic flax/epoxy laminates for both in-plane tension and bending conditions.

- From the results, it has been shown that shear stress $\left(\tau_{\mathrm{xy}}\right)$ in angle-ply is higher than the stress $\left(\sigma_{\mathrm{y}}\right)$, and this leads to laminate twisting under bending loads.

- The laminate (angle-ply) presents much higher mid-span deflection than symmetric unidirectional, cross-ply, quasi-isotropic flax/epoxy laminates.

In summary, for the numerical models developed as a tool has been found effective and powerful in predicting mechanical performance and stress/strain fields of flax fibre reinforced epoxy composite laminates loaded in tension and bending. Future experiments are planned to study mechanical properties for the four symmetrical layups of flax/epoxy composites and evaluate theoretical/numerical results presented in the article.

\section{ACKNOWLEDGEMENTS}

Financial support provided by the Welsh Government and Higher Education Funding Council for Wales through the Sêr Cymru National Research Network for Low Carbon, Energy and Environment (NRN-LCEE). This work forms part of the "Plants and Architecture" cluster.

\section{REFERENCES}

1. Pickering, K., 'Properties and performance of natural -fibre composites', 1st Edition (Woodhead Publishing, Cambridge, 2008).

2. Pickering, K.L., Aruan Efendy, M.G., Le, T.M., 'A review of recent developments in natural fibre composites and their mechanical performance', Composites: Part A, 2016, Vol. 83, 98-112.

3. Yan, L., Chouw, N. and Jayaraman, K., 'Flax fibre and its composites - A Review', Composites Part B: Engineering, 2014, Vol. 56, 296 - 317.

4. Van den Brink, W.M., Van de Vrie, G., and Nawijn, M., Modelling and simulation of damage in woven fabric composites on meso-macro level using the independent mesh 
method, International Journal of Materials Engineering Innovation, 2013, Vol. 4 (2), 84-100.

5. Lilholt, H., and Madsen, Bo., Natural composites: Cellulose fibres and the related performance of composites, International Journal of Materials Engineering Innovation, 2014, Vol. 5 (2), 100-111.

6. Edgars, S., 'Mechanical Properties of flax fibers and their composites', Licentiate thesis (Luleå University of Technology, Sweden, 2006).

7. Aslan, M., Sørensen, B.F. and Madsen, B. 'Characterization of flax fibres \& flax fibre composites: Bending cellulose based sources of materials', PhD Thesis (DTU Wind Energy, Denmark, 2012).

8. Durai Prabhakaran, R.T., 'A critical review on future materials for wind turbine blades', International Journal of Materials Engineering Innovation, 2014, Vol. 5 (2), 81-99.

9. George, J., Ivens, J. and Verpoest, I., 'Mechanical properties of flax fibre reinforced epoxy composites', Die Angewandte Makromolekulare Chemie, 1999, Vol. 272, 41-45.

10. Cerbu, C., 'Practical solution for improving the mechanical behaviour of the composite materials reinforced with flax woven fabric', Advances in Mechanical Engineering, 2015, Vol. 7 (2), 01- 11.

11. Durai Prabhakaran, R.T., Madsen, Bo., Toftegaard, H. and Markussen, C.M., 'Flexural Properties of Hybrid Natural Composite: Micromechanics and Experimental Assessment', Proceedings of an International Conference, New Delhi, December, 2012 (ACMFMS, IIT Delhi, 2012) 469 - 472.

12. Durai Prabhakaran, R.T., Toftegaard, H., Markussen, C.M. and Madsen, Bo., 'Experimental and Theoretical Assessment of Flexural Properties of Hybrid Natural Fibre Composites', Acta Mechanica., 2014, Vol. 225 (10), 2775 - 2782.

13. Durai Prabhakaran, R.T., Ormondroyd, G.A., Guan Zhongwei, Simulation of Flexural Stresses of Layered Natural Fibre/Epoxy Composite Beams, Proceedings of 4th Brazilian Conference on Composite Materials, Rio De Janeiro, July 22nd - 25th 2018.

14. Giuseppe P., Davide T., Antonio M., Thermo-Mechanical Behaviour of Flax-Fibre Reinforced Epoxy Laminates for Industrial Applications, Materials, 2015, Vol 8, 7371 -7388 .

15. George J., Van de Weyenberg I., Ivens J., Verpoest I., "Mechanical properties of flax fibre reinforced epoxy composites”, Die Angewandte Makromolekulare Chemie, 1999, Vol. 272, 41-45. 
16. Van de Weyenberg I., Ivens J., De Coster A., Kino B., Baetens E., Verpoest I., "Influence of processing and chemical treatment of flax fibres on their composites", Composites Science and Technology, 2003, Vol. 63, 1241-1246.

17. Van de Weyenberg I., Truong T.C., Vangrimde B., Verpoest I., "Improving the properties of UD flax fibre reinforced composites by applying an alkaline fibre treatment", Composites Part A: Applied Science and Manufacturing, (In Press).

18. Michelena, A.H., G-Jones, J., Summerscales, J., Hall, W., Silane modification of the flax/epoxy system interface, Procedia Engineering, 2017, Vol 200, 448 - 456.

19. Rayyaan, R., Kennon, W.R., Potluri, P., Akonda, M., Morphological modification of the technical flax fibre bundles to improve the longitudinal tensile properties of flax fibre reinforced epoxy composites, Applied Physics, 2018.

20. Agarwal, B.D., Broutman, L.J. and Chandrashekhara, K., 'Analysis and performance of fiber composites', 3rd Edition (John Wiley \& Sons, Inc., New Delhi, 2006).

21. Wambua, P, Ivens, J, Verpoest, I. Natural fibres: Can they replace glass in fibre reinforced plastics? Compos Sci Technol 2003, Vol. 63, 1259-1264.

22. Dillon, B., Sadeghian, P., and Fam, A., Tensile properties of flax FRP composites, 6th Asia-Pacific Conference on FRP in Structures, Singapore, 19-21st July 2017.

23. Qi, Y., Li, J., and Liu, L., Stiffness prediction of multi-layer connected biaxial weftknitted fabric-reinforced composites, Journal of Reinforced Plastics and Composites, 2015, Vol.34(14), 1113-25

24. Reissner, E., and Y. Stavsky, Bending and stretching of certain types of heterogeneous aerolotropic elastic plates, Journal of Applied Mechanics, Vol. 28, 1961, 402-408.

25. Whitney, J.M., Pagano, N.J., Shear deformation in heterogeneous anisotropic plates, Journal of Applied Mechanics, Vol. 37, 1970, 1031-1036.

26. SAVITHRI S. and VARADAN, T.K., Accurate bending analysis of laminated orthotropic plates, AIAA Journal, 1990, Vol. 28, No. 10, 1842-1844.

27. Reddy, J.N. and Kuppusamy, T., Analysis of layered composite plates by threedimensional elasticity theory, Technical Report: VPI - E - 82 - 31, 1982, Department of NAVY, Virginia, USA.

28. Reddy, J. N., Barbero, E.J., A plate bending element based on a generalised laminate plate theory, International Journal for Numerical Methods in Engineering, 1989, Vol. $28,2275-2292$. 
29. Sarvestani, H.Y., Naghashpour, A., Heidari-Rarani, M., Bending analysis of a general cross-ply laminate using 3D elasticity solution and layerwise theory, International Journal of Advanced Structural Engineering, 2015, Vol. 7, 329-340.

30. Stalin, B., and Athijayamani, A., The performance of bio waste fibres reinforced polymer hybrid composite, International Journal of Materials Engineering Innovation, 2016, Vol. 7 (1), 15-25.

31. De Rosa I. M., Kenny J. M., Puglia D., Santulli C., Sarasini F. Morphological, thermal and mechanical characterization of okra (Abelmoschusesculentus) fibres as potential reinforcement in polymer composites. Compos. Sci. Technol., 2010, Vol. 70, 116-122.

32. Bergès, M., Leger, R., Person, V., Placet, V., Ramasso, E., Rousseau, J., Gabrion, X., Corn, S., Fontaine, S., Ienny, P., Effect of moisture uptake on flax fibre-reinforced composite laminates: Influence on dynamic and Quasi-Static properties, Proceedings of 17th European Conference on Composite Materials, Munich, Germany, 26-30th June 2016.

33. Rask, M., \& Madsen, B. (2011). Twisting of fibres in yarns for natural fibre composites. Abstract from 18th International Conference on Composite Materials, Jeju Island, Korea, Republic of.

34. Durai Prabhakaran, R.T., Lilholt, H., Aviles, F., Løgstrup Andersen, T., \& Knudsen, H. (2013). Fibre waviness and misalignment measurement of unidirectional glass/LPET commingled composites - Effect on mechanical properties. Proceedings of the Ris $\varnothing$ International Symposium on Materials Science, 34, 349-363.

35. Bos, H. L., Van den Oever, M. J. A., Peters, O. Tensile and compressive properties of flax fibres for natural fibre reinforced composites. J Mater Sci, 2002, Vol. 37, 16831692.

36. Rakočević, M., Vatin, N., Bending of Laminated Composite Plates, Applied Mechanics and Materials, 2015, Vol. 725-726, 667-673.

37. Coroller, G., Lefeuvre, A., Duigou, A.L., Bourmaud, A., Ausias, G., Gaudry, T., Effect of flax fibres individualisation on tensile failure of flax/epoxy unidirectional composite, Composites Part A: Applied Science and Manufacturing, 2013, Vol. 51, 62-70. 

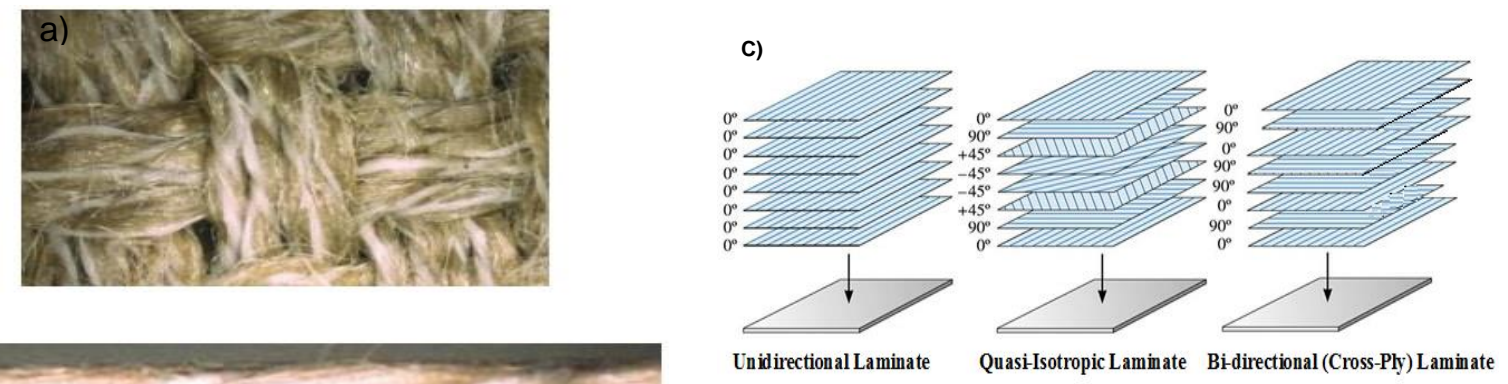

Figure 1: Bidirectional flax fabrics, fibre bundle kinking pattern, and symmetric laminates: layup's with varying lamina fibre orientations

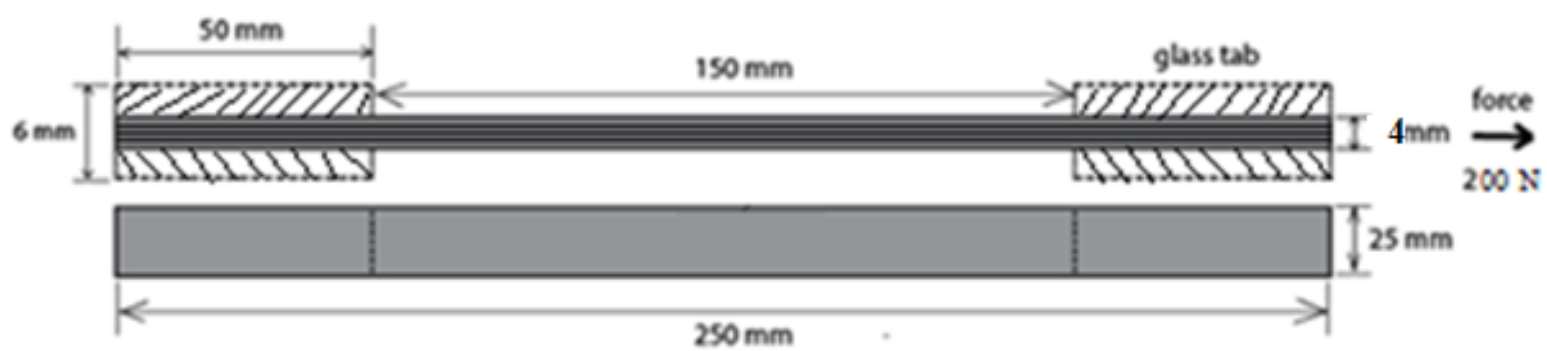

Figure 2: Tensile test specimen geometry of layered flax/epoxy composite 

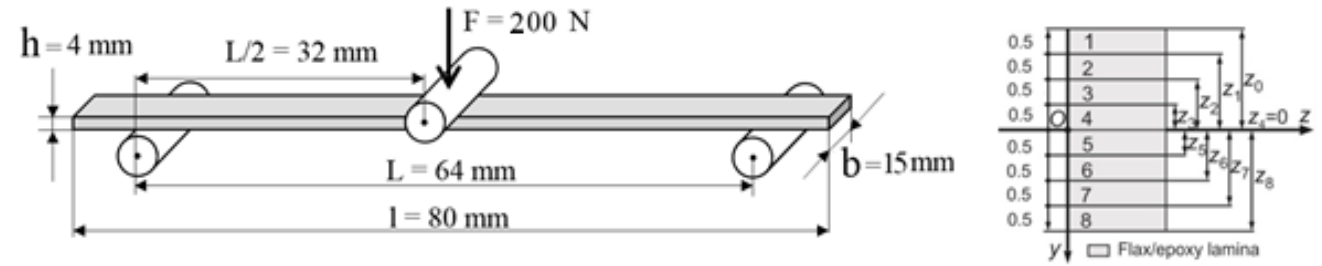

Figure 3: a) Load configuration of 3 point bending b) Thickness and coordinates of the laminae
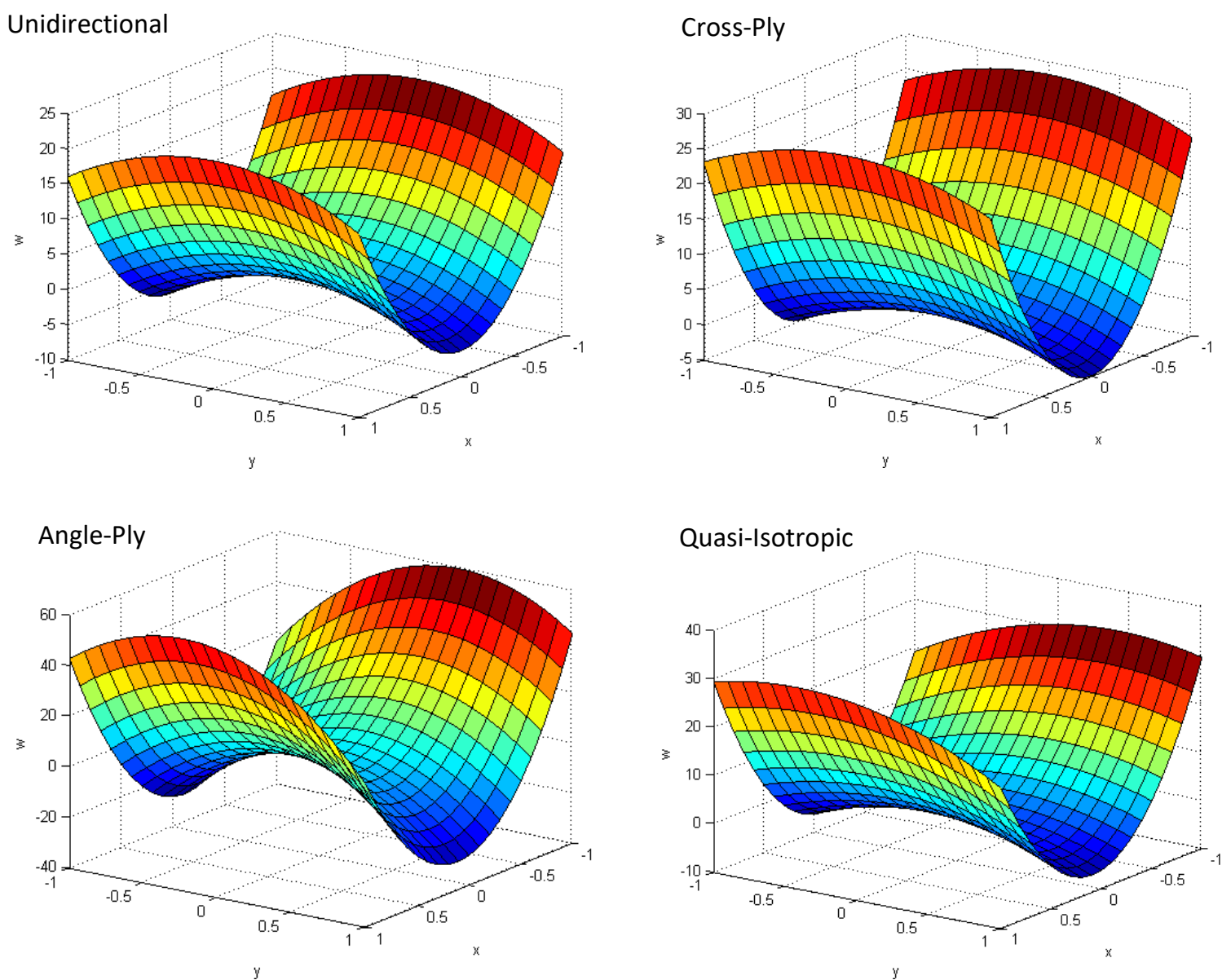

Figure 4. Flax fibre/epoxy laminate deformation under pure bending 


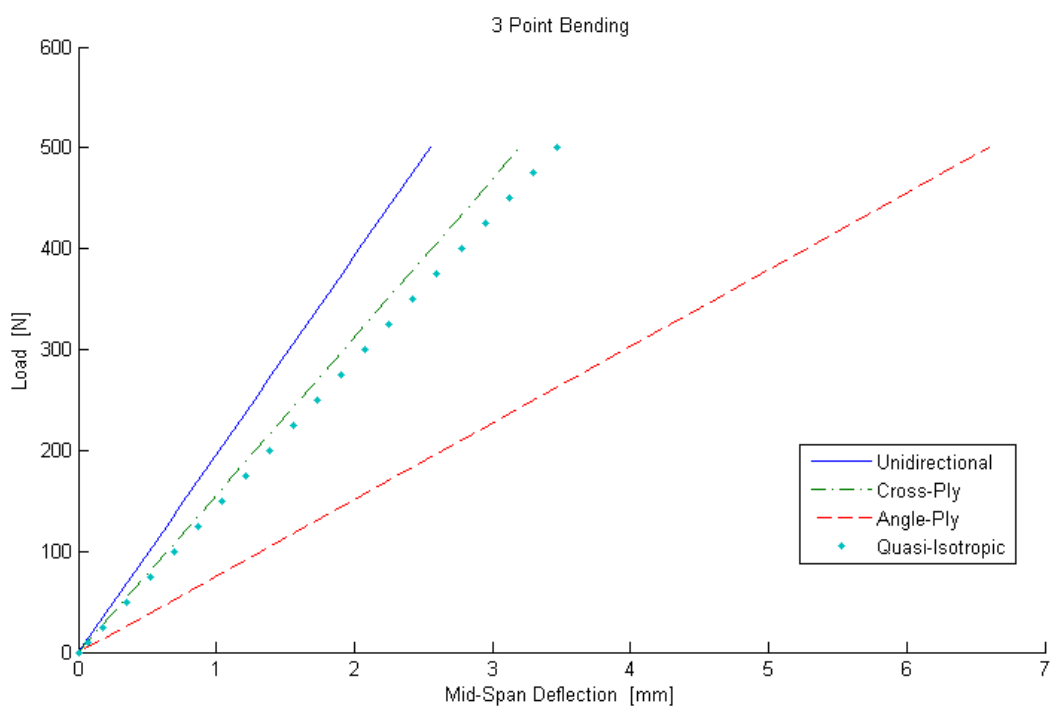

Figure 5: Load-deflection curve under 3-point bending of a layered flax/epoxy composite beam
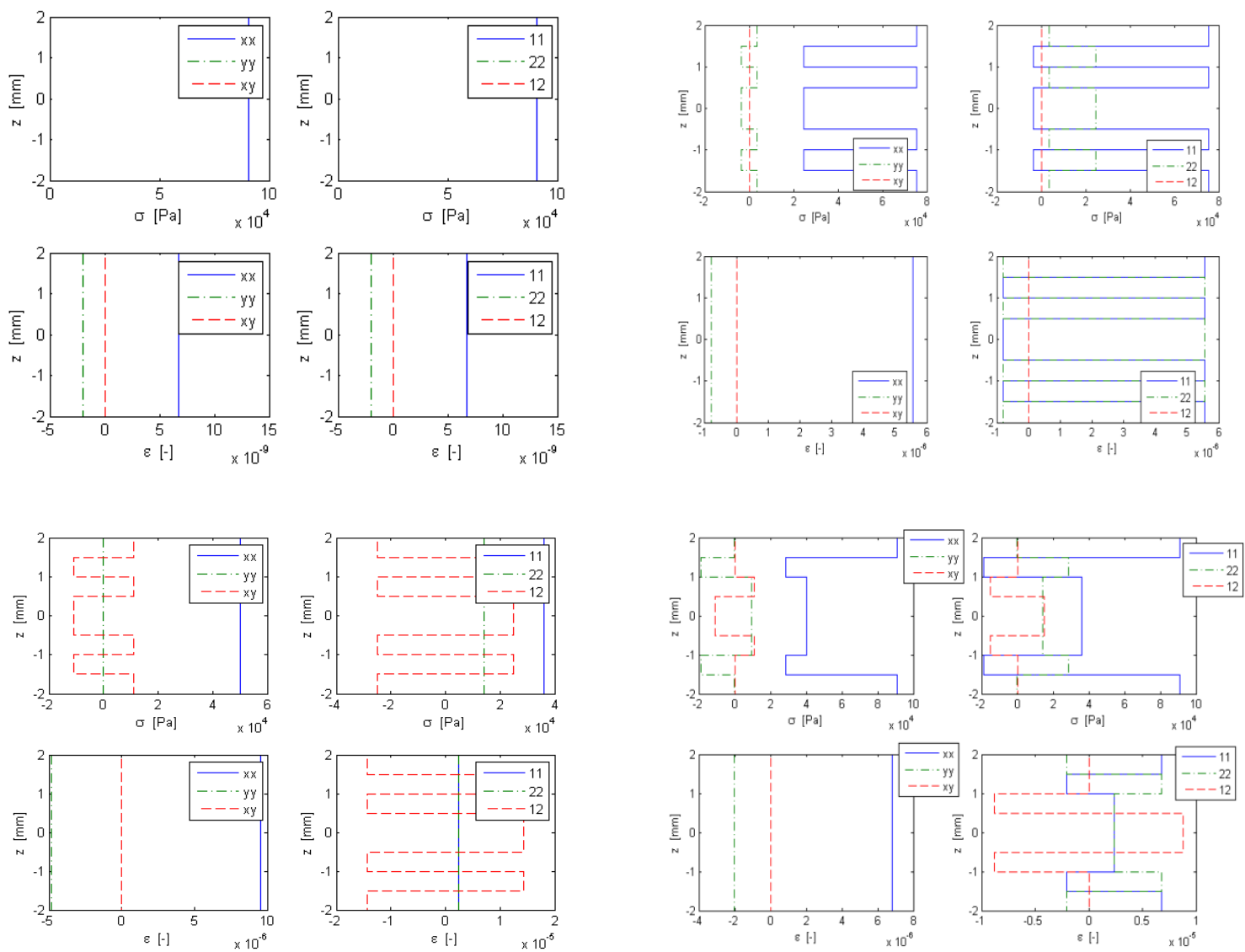

Figure 6. Through-the-thickness distribution of in-plane tensile stress/strains for flax/epoxy laminate 

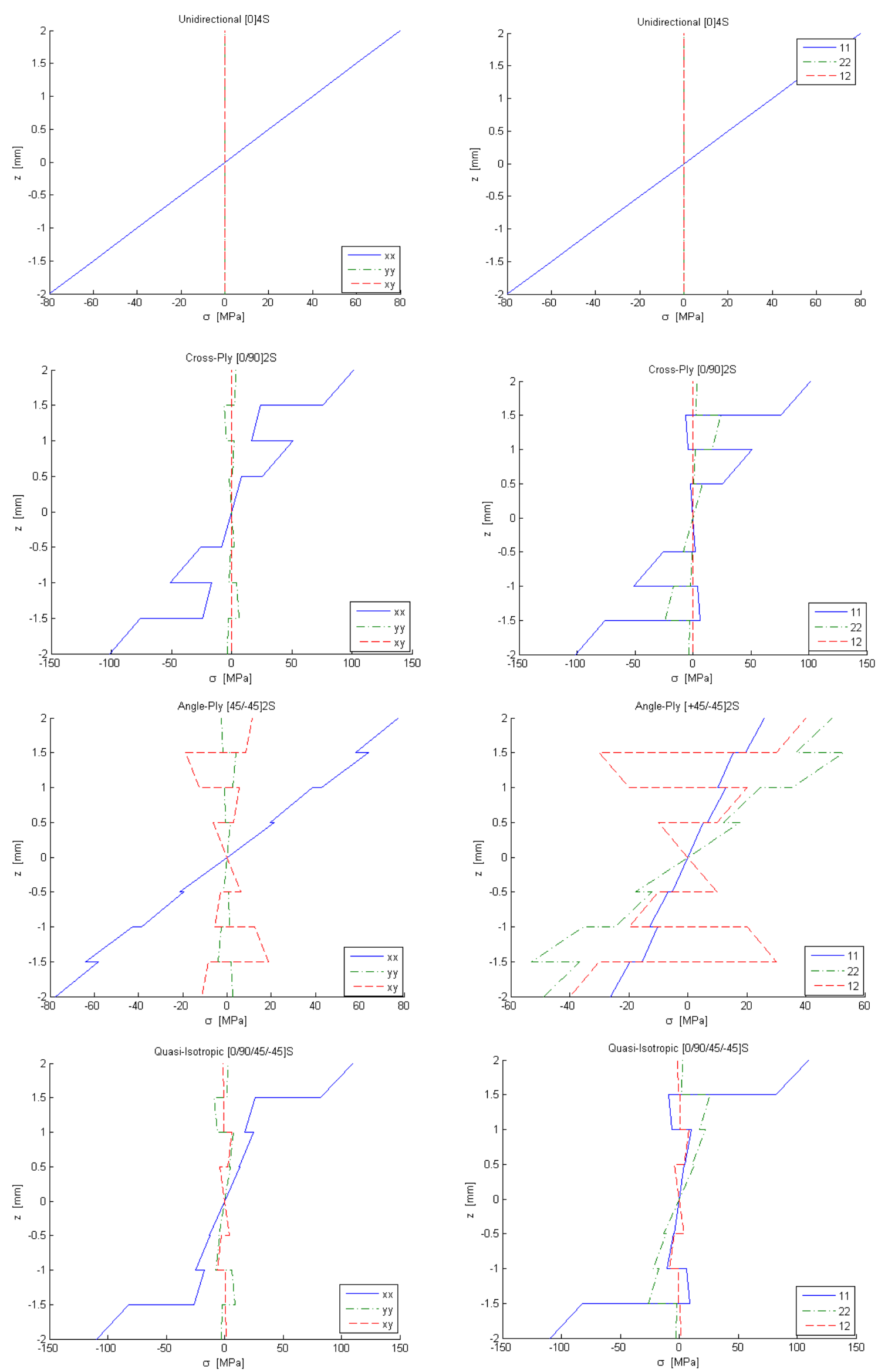

Figure 7. Through-the-thickness distribution of in-plane stress in bending for a flax/epoxy laminate 
Unidirectional
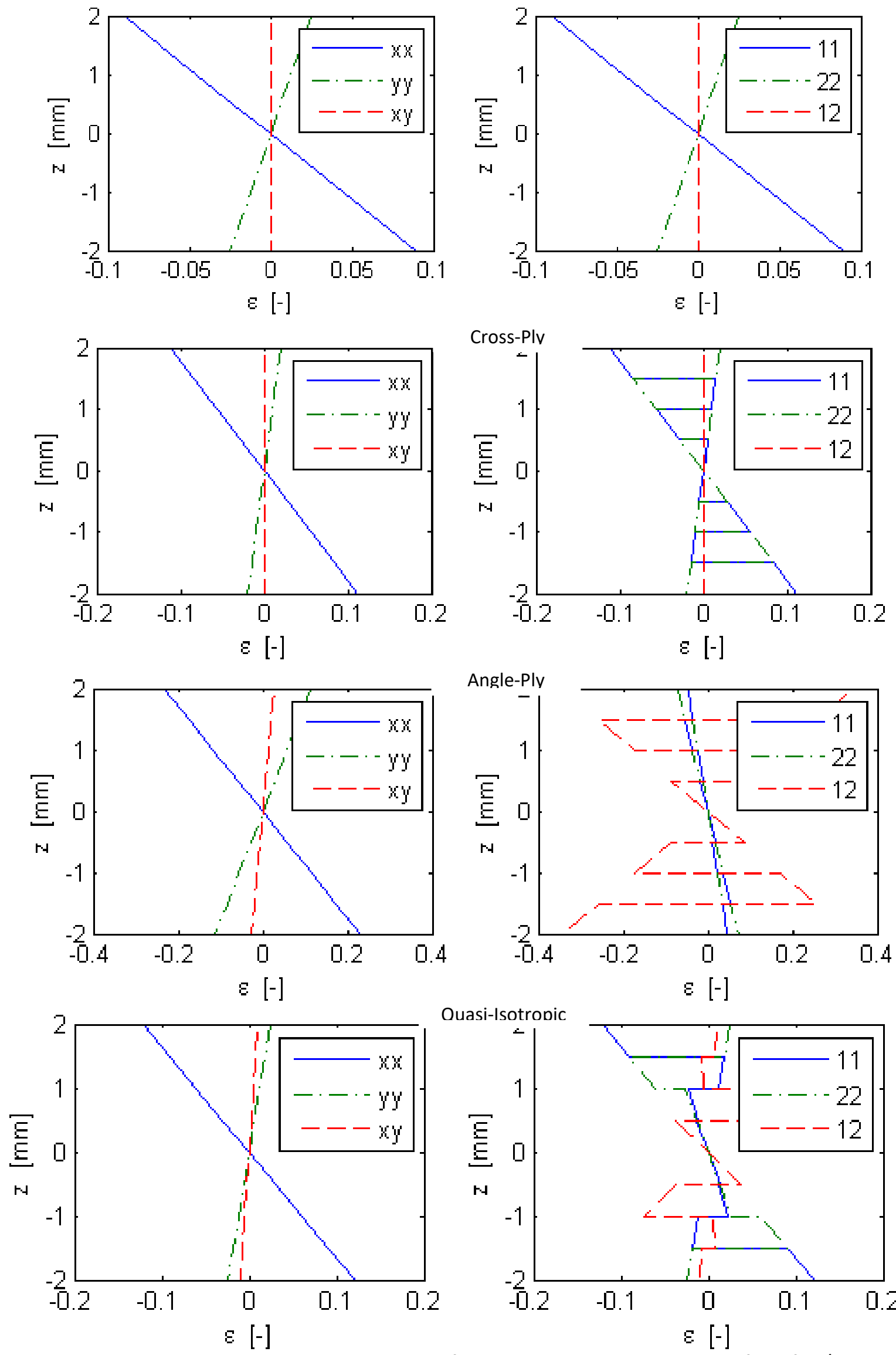

Quasi-Isotropic

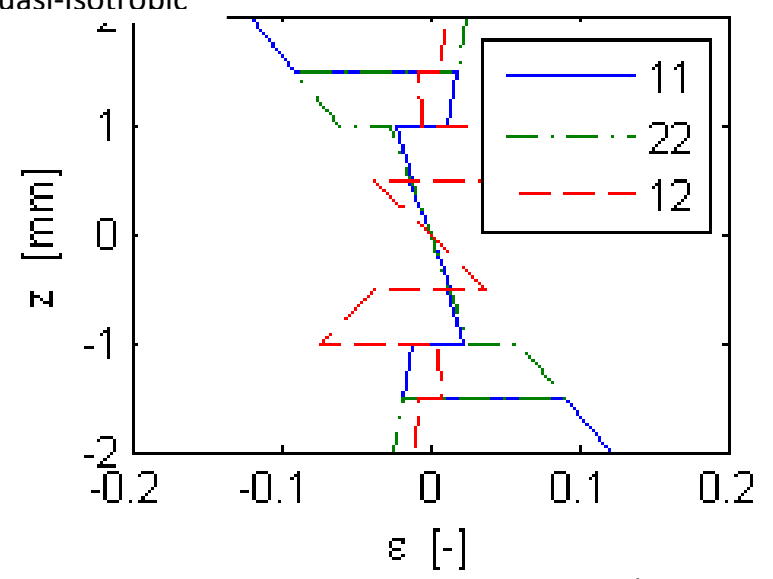

Figure 8. Through-the-thickness distribution of the in-plane strains in bending for a flax/epoxy laminate 


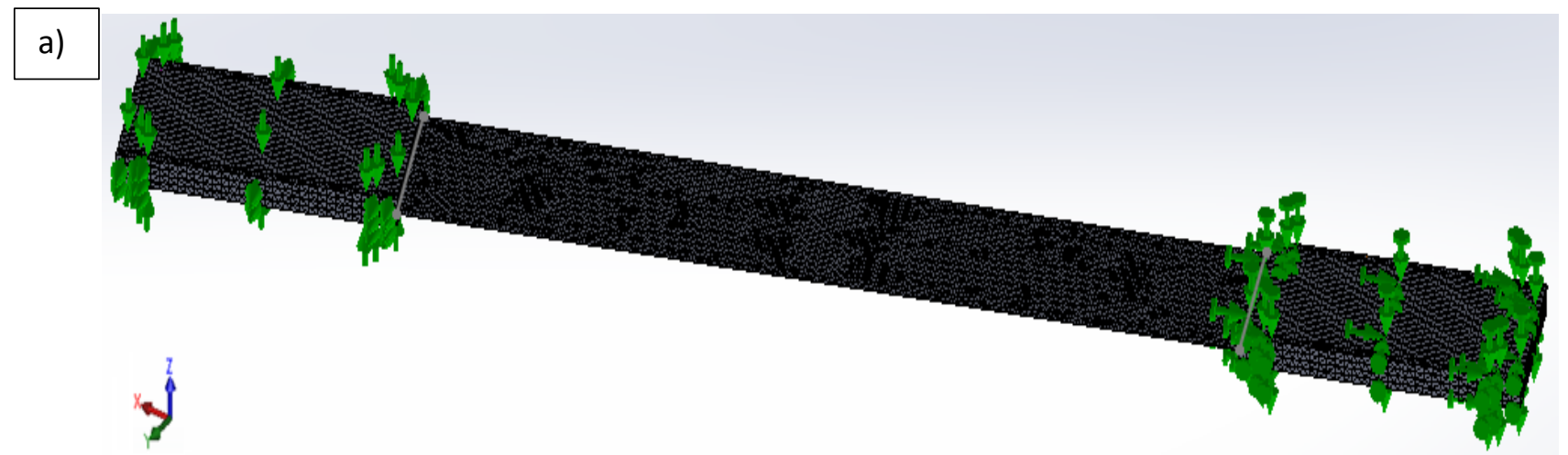

\section{b)}

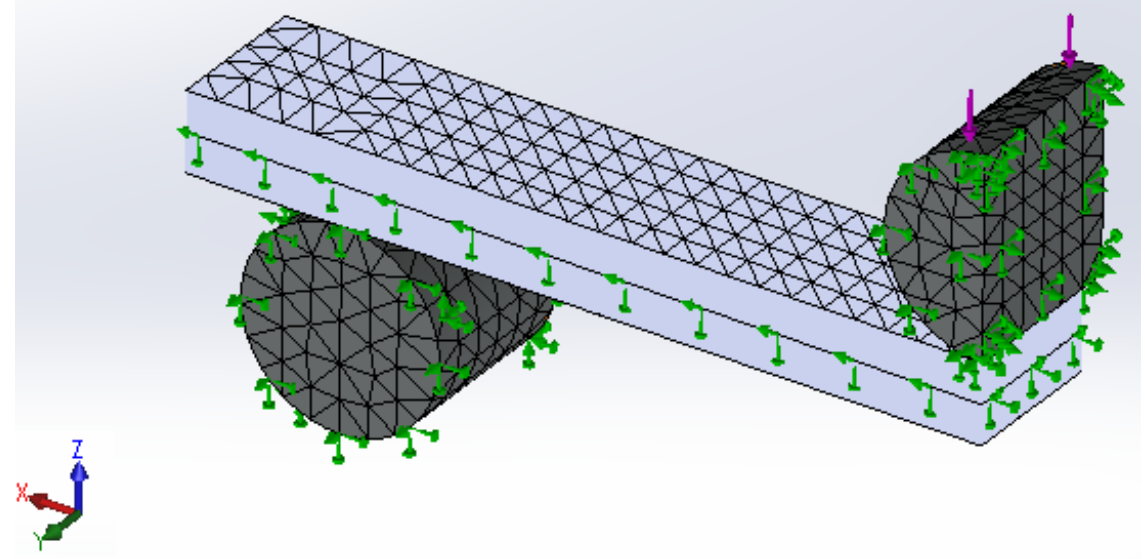

Figure 9. Mesh plot for laminate tensile and bending simulations
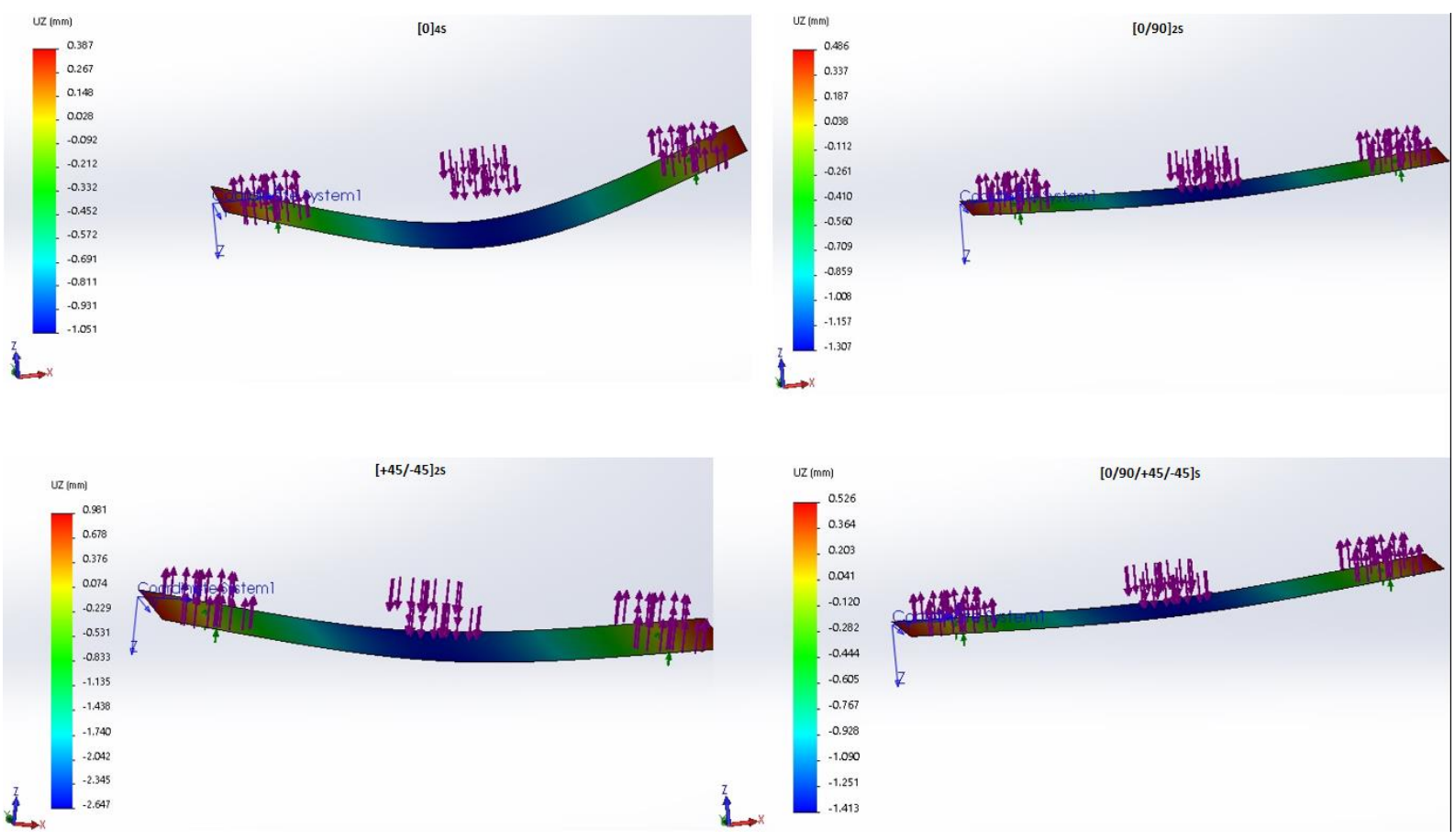

Figure 10. Simulation for mid-span deflection of for a flax/epoxy laminate under flexural load 


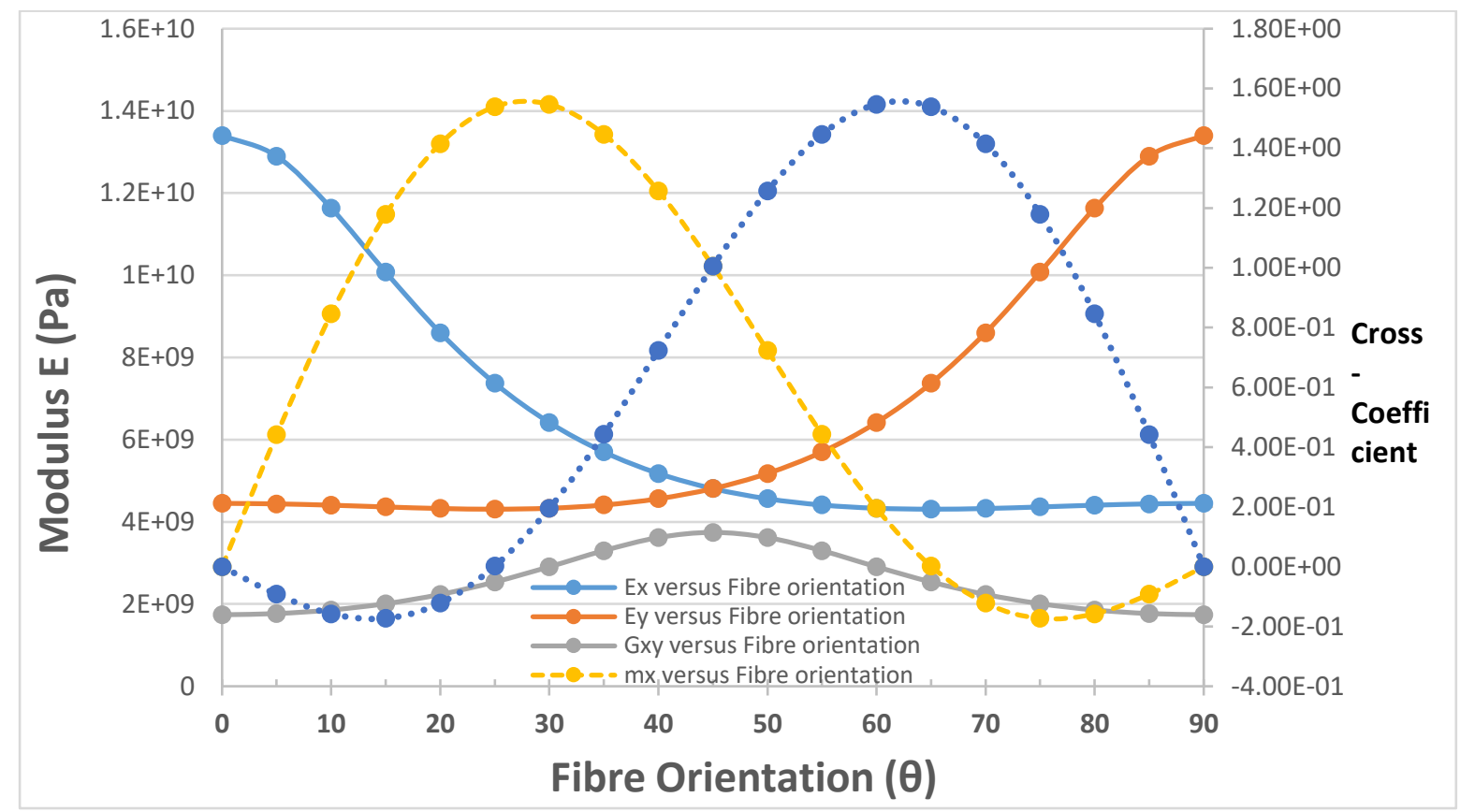

Figure 11. Elastic Constants of a flax-epoxy laminae: variation with fibre orientation

UD Ply 2

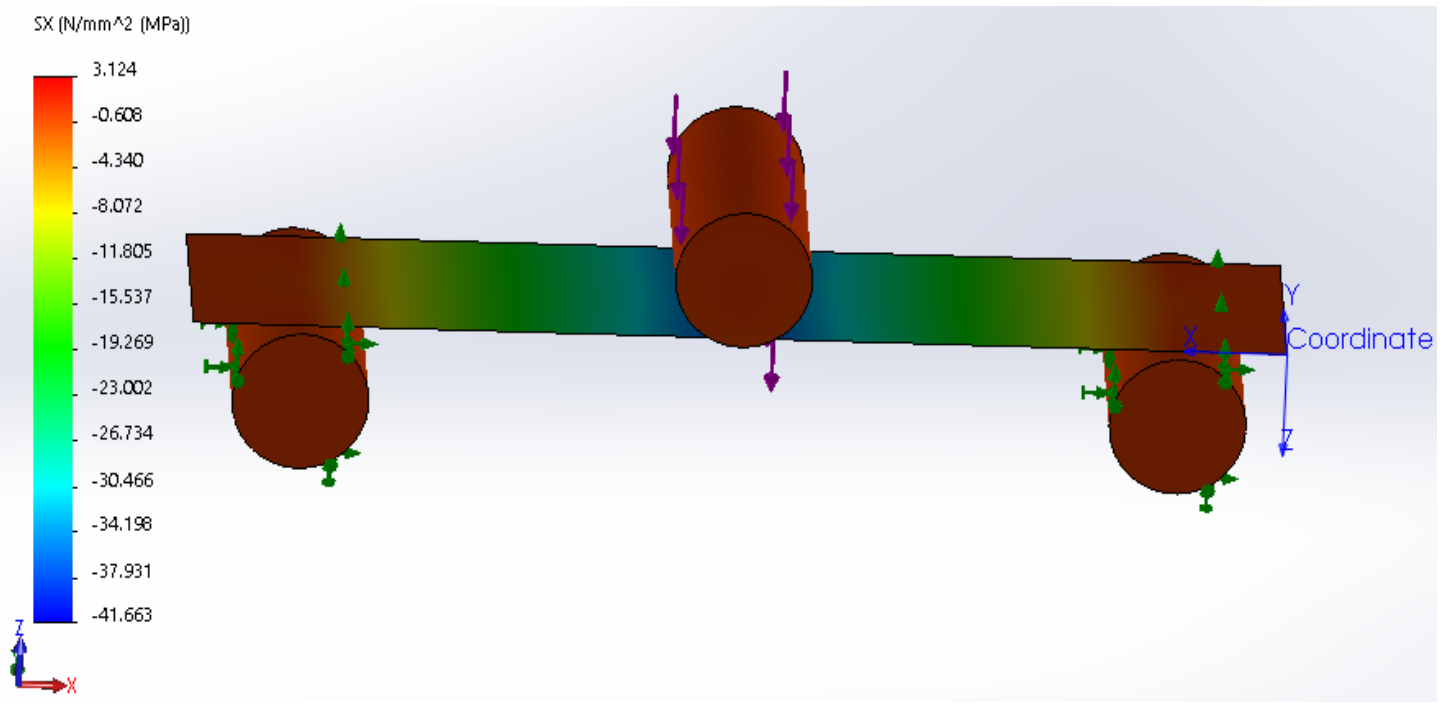

Figure 12: Ply Stresses for Unidirectional $[0]_{4 \mathrm{~s}}$ Flax/Epoxy Composite 
Table 1: Material properties of fibre, matrix and laminae [12]

\begin{tabular}{|c|c|c|c|c|c|c|}
\hline & & \multicolumn{5}{|c|}{ Fibre - Flax fibre } \\
\hline Symbol & $V_{f} \quad(\%)$ & \begin{tabular}{|ll}
$E_{1 f}$ & $(\mathrm{GPa})$
\end{tabular} & $E_{2 f} \quad(\mathrm{GPa})$ & $G_{f} \quad(\mathrm{GPa})$ & $\vartheta_{f}$ & $\rho_{\mathrm{f}}\left(\mathrm{g} / \mathrm{cm}^{3}\right)$ \\
\hline Value & 0.275 & 39.0 & 5.44 & 3.46 & 0.11 & 1.516 \\
\hline \multicolumn{7}{|c|}{ Matrix-Epoxy resin } \\
\hline Symbol & $V_{m}$ & \begin{tabular}{|ll}
$E_{m}$ & $(\mathrm{GPa})$ \\
\end{tabular} & - & $G_{m}(\mathrm{GPa})$ & $\vartheta_{m}$ & $\rho_{m}\left(g / \mathrm{cm}^{3}\right)$ \\
\hline Value & 0.725 & 3.70 & - & 1.37 & 0.35 & 1.152 \\
\hline \multicolumn{7}{|c|}{ Laminae - Flax/Epoxy single ply } \\
\hline Symbol & - & \begin{tabular}{|ll}
$E_{1}$ & $(\mathrm{GPa})$ \\
\end{tabular} & \begin{tabular}{|ll}
$E_{2}$ & $(\mathrm{GPa})$ \\
\end{tabular} & $G_{12}(\mathrm{GPa})$ & $\vartheta_{12}$ & $\rho_{c}\left(g / \mathrm{cm}^{3}\right)$ \\
\hline Value & - & 13.4 & 4.45 & 1.74 & 0.284 & 1.2794 \\
\hline
\end{tabular}

Table 2: Transformed Stiffness Matrix of Laminates with 0, 90, 45, -45 orientations

\begin{tabular}{|c|c|c|c|c|c|c|c|}
\hline \multirow{2}{*}{\multicolumn{2}{|c|}{$\begin{array}{l}\text { Laminae number and fibre } \\
\text { angle } \theta \\
\text { (ply thickness is } 0.5 \mathrm{~mm} \text { ) }\end{array}$}} & $\bar{Q}_{11}$ & $\bar{Q}_{22}$ & $\bar{Q}_{12}$ & $\bar{Q}_{66}$ & $\bar{Q}_{16}$ & $\bar{Q}_{26}$ \\
\hline & & \multicolumn{6}{|c|}{$\mathrm{MPa}$} \\
\hline \multicolumn{8}{|c|}{ Unidirectional Laminates $\left[0^{\circ}\right]_{4 \mathrm{~s}}$} \\
\hline $\begin{array}{l}1^{\text {st }}, 2^{\text {td }}, 3^{\text {rd }}, 4^{\text {th }} \mathrm{Ply} \\
5^{\text {th }}, 6^{\text {th }}, 7^{\text {th }}, 8^{\text {th }} \mathrm{Ply}\end{array}$ & $0^{0}$ & 13769 & 4572 & 1298 & 1740 & 0 & 0 \\
\hline \multicolumn{8}{|c|}{ Cross-Ply Laminate $[0 / 90]_{2 \mathrm{~s}}$} \\
\hline $1^{\text {st }}, 3^{\text {rd }}, 6^{\text {th }}, 8^{\text {th }} \mathrm{Ply}$ & $0^{0}$ & 13769 & 4572 & 1298 & 1740 & 0 & 0 \\
\hline $2^{\text {nd }}, 4^{\text {rd }}, 5^{\text {th }}, 7^{\text {th }} \mathrm{Ply}$ & $90^{\circ}$ & 4572 & 13769 & 1298 & 1740 & 0 & 0 \\
\hline \multicolumn{8}{|c|}{ Angle-Ply Laminate $[+45 /-45]_{2 \mathrm{~s}}$} \\
\hline $1^{\text {st }}, 3^{\text {rd }}, 6^{\text {th }}, 8^{\text {th }} \mathrm{Ply}$ & $+45^{0}$ & 6975 & 6975 & 3495 & 3936 & 2299 & 2299 \\
\hline $2^{\text {nd }}, 4^{\text {rd }}, 5^{\text {th }}, 7^{\text {th }}$ Ply & $-45^{0}$ & 6975 & 6975 & 3495 & 3936 & -2299 & -2299 \\
\hline \multicolumn{8}{|c|}{ Quasi-Isotropic Laminate $[0 / 90 /+45 /-45]_{\mathrm{s}}$} \\
\hline $1^{\text {st }}$ and $8^{\text {th }}$ Ply & $0^{0}$ & 13769 & 4572 & 1298 & 1740 & 0 & 0 \\
\hline $2^{\text {nd }}$ and $7^{\text {th }}$ Ply & $90^{\circ}$ & 4572 & 13769 & 1298 & 1740 & 0 & 0 \\
\hline $3^{\text {rd }}$ and $6^{\text {th }}$ Ply & $+45^{0}$ & 6975 & 6975 & 3495 & 3936 & 2299 & 2299 \\
\hline $4^{\text {th }}$ and $5^{\text {th }}$ Ply & $-45^{0}$ & 6975 & 6975 & 3495 & 3936 & -2299 & -2299 \\
\hline
\end{tabular}


Table 3: Bending Properties of Symmetric Layup Flax/Epoxy Laminates

\begin{tabular}{|c|c|c|c|c|c|}
\hline \multirow[t]{2}{*}{ Composite Plate } & $\begin{array}{l}\text { Laminate } \\
\text { Modulus } \\
\text { (In-plane }\end{array}$ & $\begin{array}{l}\text { Laminate } \\
\text { Bending } \\
\text { Modulus }\end{array}$ & $\begin{array}{c}\text { Bending } \\
\text { Stress } \\
\sigma_{f b}\end{array}$ & \multicolumn{2}{|c|}{$\begin{array}{c}\text { Mid-Span Deflection } \\
\text { at } \mathrm{F}=200 \mathrm{~N} \\
W_{0 \max }\end{array}$} \\
\hline & $\begin{array}{c}\text { Theoretical } \\
\text { (GPa) }\end{array}$ & $\begin{array}{c}\text { Theoretical } \\
\text { (GPa) }\end{array}$ & $\begin{array}{c}\text { Theoretical } \\
(\mathrm{MPa})\end{array}$ & $\begin{array}{c}\text { Theoretical } \\
\text { (mm) }\end{array}$ & $\begin{array}{l}\text { Numerical } \\
(\mathrm{mm})\end{array}$ \\
\hline Unidirectional $[0]_{4 \mathrm{~S}}$ & 13.4 & 13.4 & 79.8 & 1.02 & 1.051 \\
\hline Cross Ply & 8.98 & 10.7 & 79.8 & 1.28 & 1.307 \\
\hline Angle Ply $[+45 /-45]_{2 \mathrm{~S}}$ & 5.22 & 5.18 & 80.2 & 2.64 & 2.647 \\
\hline $\begin{array}{l}\text { Quasi-Isotropic } \\
{[0 / 90 / 45 /-45]_{S}}\end{array}$ & 7.36 & 9.85 & 79.9 & 1.39 & 1.413 \\
\hline
\end{tabular}




\section{Biographical Notes:}

Dr R.T. Durai Prabhakaran is a Sêr Cymru Fellow and materials scientist with an interest in polymer composites, design and manufacturing, natural fibre and biopolymer composites. He has worked on a range of projects including: screening and material characterization of advanced composites for future large wind turbine blades in a Danish funded project (BLADE KING), Composites recycling in a EPSRC funded project (TARF - LCV), and a hybrid (natural/glass) fibre bio-based polymer composites in a European funded project (NATEX). $\mathrm{He}$ is a Fellow of the Indian Institute of Metals (IIM) and a Member of the Society for the Advancement of Material and Process Engineering (SAMPE, USA).

Mr Mohit Gupta is a PhD scholar in the department of Applied Mechanics at Indian Institute of Technology, New Delhi (IIT Delhi). He is currently working in the area of Multi-scale Modelling of Polymer Composites. He has published 3 articles in the journal and conference proceedings.

Dr Puneet Mahajan is a Professor in the department of Applied Mechanics at Indian Institute of Technology, New Delhi (IIT Delhi). He has several ongoing research projects, micromechanics of Carbon-Carbon composites, impact behaviour of composites, and constitutive behaviour of snow. Thirteen students have finished $\mathrm{PhD}$ under his guidance. $\mathrm{He}$ has more than 70 articles in international Journals.

Dr Graham A Ormondroyd is a materials scientist who specialises in bio-based materials and timber. He manages the material research group at the BioComposites Centre, which includes a portfolio of commercial and project work. Graham is a PRINCE2 practitioner, a Fellow of the Institute of Materials Minerals and Mining and have more than 40 journal articles in international repute. 